\title{
An Experience of Liquid Glass Mixture Using for Alphaset Process in Russia
}

\author{
Kukartsev Viktor Alekseevich ${ }^{1, a}$, Kukartsev Vladislav Viktorovich ${ }^{1,2, ~ b}$, \\ Tynchenko Vadim Sergeevich ${ }^{1,2, c^{*}}$ \\ ${ }^{1}$ Siberian Federal University, Svobodny 79, Krasnoyarsk 660041, Russia \\ ${ }^{1}$ Siberian State University of Science and Technology, 31, Krasnoyarsky Rabochy Av., 660037 \\ Krasnoyarsk, Russia \\ asarabernar777@mail.ru, bvlad_saa_2000@mail.ru, cvadimond@mail.ru
}

Keywords: AlpHaset process, resin, hardener, liquid glass, liquid-glass mixture regenerate.

\begin{abstract}
Features of a technology application AlpHaset process in Russia are considered. Requirements imposed on the used materials, especially to forming sand. The reasons, which lead to searching of the technology, eliminating defects of this process. The capability of using resins and hardeners of the Russian fabricator. The question about the opportunity substitution of resin for liquid glass for this process was elaborated. There was the experience of AlpHaset technology process was learned, with use of a liquid glass, the extent of a regeneration of such mix at the factories of Russia is also studied. Laboratory studies were done and recipe of the mixture was created for AlpHaset process, where a resin is completely replaced with a liquid glass. At the same time, the work on receiving a reclaim from an aged dump of liquid glass mix was completed, which could serve as a substitute of fresh sand in a compounding for AlpHaset process. At the result, there was created and embedded recipe of the mix, where the reclaim (which is completely replacing fresh forming sand), received from aged dumps of traditional liquid glass mix for process $\mathrm{CO} 2$, was used. The compounding of forming mix began to look as follows: a reclaim of liquid glass mix, a reclaim from the line, a liquid glass, and hardener.
\end{abstract}

\section{Introduction}

Over the last few years, the AlpHaset process is being actively introduced in foundries in Russia, which use materials not only from foreign manufacturers but also from Russian enterprises [1-6]. A considerable volume of resins and catalysts is produced by Ltd. "Uralchimplast", which monitors the work of enterprises using their products. As a result of the analysis carried out by this firm, to obtain the necessary technological properties, the mixture based on Russian sands in these enterprises contains 1.8-2 parts by weight of resin and 25-35\% of the catalyst. For this reason, the advantages of the AlpHaset process are reduced, namely:

1. There is a significant smell not only in the area of pouring and punching but also on molding;

2. It is difficult to clean the mixer with water;

3. It is difficult to extract a half-mold or a rod from a tooling (Fig. 1);

4. The breakdown of the mixture deteriorates when makes castings of complex geometry;

5. The increased consumption of resin and hardener leads to an increase in the cost of materials, and hence the produced castings.

Relying on the foregoing, it follows that the use of the AlpHaset process, based on its merits, is only useful when using materials that meet the requirements of the developers of the AlpHaset system.

However, it should not be forgotten that molding and core mixtures with the use of liquid glass as a binder are still widely used throughout the world, making it possible to produce castings of high quality, have a low cost and environmental safety for workers [7-9]. A clear confirmation is the data given in Table 1 [10-12]. 


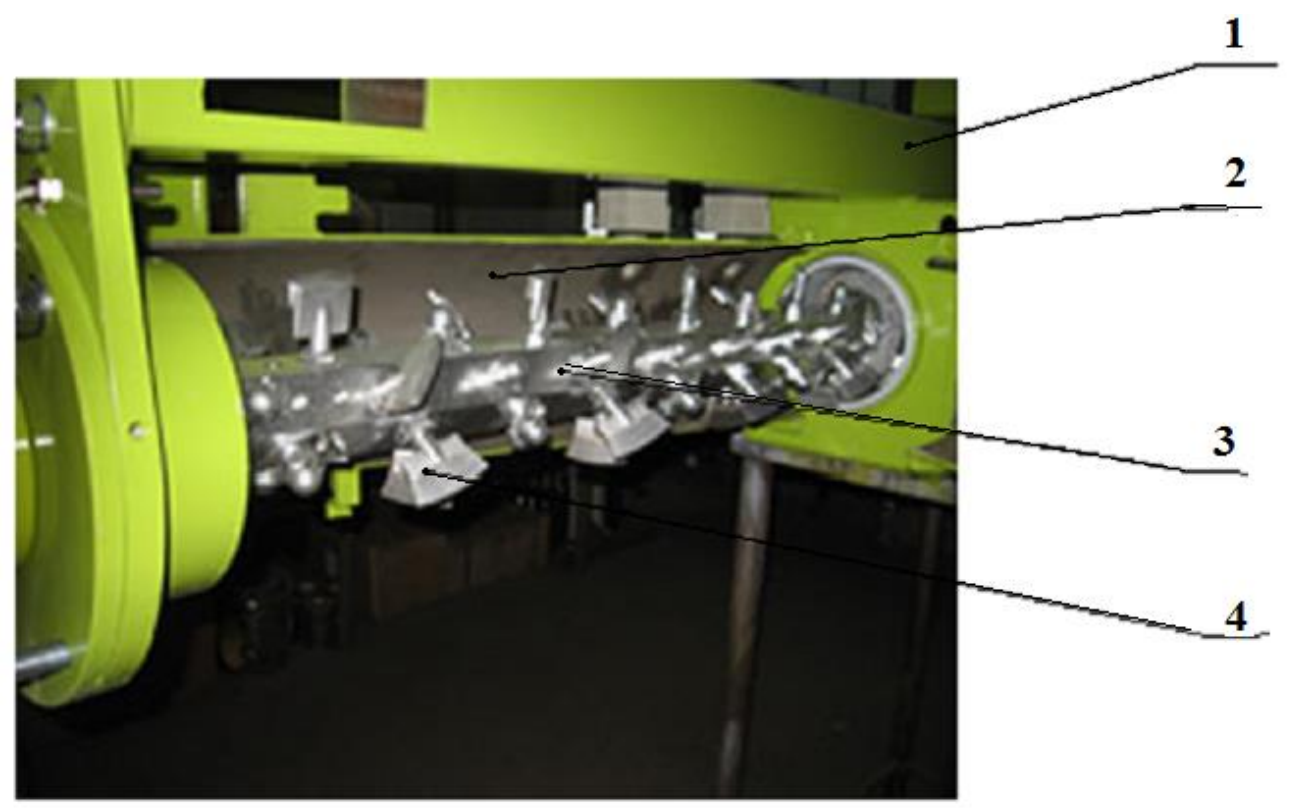

Fig. 1. Mixer screw: 1 - mixer console, 2 - screw casing, 3 - shaft, 4 - screw shovels.

Table 1. Annual consumption of binders in countries with a well-developed foundry, [ton].

\begin{tabular}{|l|l|l|l|l|}
\hline Country & Cold-curing resins & Hot-curing resins & \multicolumn{2}{|c|}{ Liquid glass } \\
\cline { 4 - 5 } & & & $\begin{array}{l}\text { For the } \\
\mathrm{CO}_{2} \text {-process }\end{array}$ & $\begin{array}{l}\text { For mixtures with } \\
\text { esters }\end{array}$ \\
\hline France & 7000 & 3200 & 9000 & 800 \\
\hline Germany & 12000 & 6000 & 5200 & 800 \\
\hline Japan & 3500 & No data & 100000 & 1200 \\
\hline UK & 10000 & 5000 & 27600 & 9000 \\
\hline USA & 26200 & 28900 & 18000 & 18000 \\
\hline
\end{tabular}

The difference in consumption of liquid glass is associated with the available reserves of high-quality sands, so Japan, which doesn't have good sands, uses liquid-glass mixtures on a large scale.

In our country, according to the data of foundries listed on the website of RCA, out of 240 factories (the figure is constantly changing), 22 of them use the technology for making molds and rods using liquid glass [13].

However, liquid-glass mixtures are not without flaws [14]. Their main negative quality is a high residual strength (strength after heating the mixture, due to the effect of the cast metal on the molding and core mixtures). High values of residual strength are the main cause of poor knockout of the LGM, high energy consumption for removal of the rod (mixture) from the cast (shape). Poor knockout significantly complicates and lengthens the technological cycle, increases the cost price and in some cases worsens the quality of the castings. This disadvantage (along with poor regeneration) drastically reduces all other advantages of the LGM [15]. For this reason works on improvement of property of liquid glass mix, first of all, due to use of the additives allowing to reduce the amount of liquid glass in a mix compounding are constantly conducted [16,17].

\section{Results and discussion}


For foundries operating automatic molding lines working on the $\alpha$-set process (especially those working on molding sands that do not meet the requirements of the $\alpha$-set system), it would be advantageous to work on a mixture in which the resin is replaced by a liquid glass.

At one of such enterprises, using the automatic molding line of IMF, designed to produce safety-free forms in the $\alpha$-set process, work on testing the technology of manufacturing not only molds but also rods from a mixture in which the resin was replaced by the liquid glass was carried out. The set of line equipment included a knockout grate with a mechanical regeneration unit using the effect of a fluidized bed. This plant, when operating on a traditional mixture for an $\alpha$-set process containing resin and hardener, allowed the use of regenerate to $80 \%$ [18].

On request of the line, the mixture should have the following tensile strength, $\mathrm{kg} / \mathrm{cm} 2$ : after $25-30$ min-0,7-0,9; after $60 \mathrm{~min}-1,3-1,7$; after $120 \mathrm{~min}-2,2-2,7$. Strength 0,7-0,9 is necessary for qualitative extraction of half-molds from the box, if the strength is less, the half-mold can collapse when it is removed, if the strength is higher, the half-mold can get stuck in the box. The strength of 1.3-1.7 is necessary for the smooth operation of the manipulator during transportation and canting of the half-molds. If the strength is lower, the manipulator can crush the half-mold, if the strength is higher, the manipulator spikes may not catch the half-mold, and it may fall or crack with increasing effort to take it. Strength 2.2-2.7 is necessary when pouring the assembled molds, if it is smaller, the mold cannot withstand the pressure of the cast metal.

Based on the experience of the foundry of OJSC Mikhailovsky GOK, the experimental work, under laboratory conditions, was started with the simultaneous hardening of the hardener A-10 manufactured by Ltd. "Uralchimplast" and the hardener 3CM produced by the NPO "Karbokhim". Besides that, works with only using of hardeners 3CM and ACE (hardener of English production) was carried out. On the basis of the data obtained and, taking into account economic expediency, a mixture was used for the production of moulds on the line, in which the resin was replaced with liquid glass, hardener A-10 and hardener 3CM were used simultaneously as the hardener after adjusting their contents and the possible amount of regenerate to ensure mechanical properties required on the line [19]. A lot of time was spent on the selection of the necessary density and the module of liquid glass. The results of the achieved mechanical properties of various mixture formulations obtained under laboratory conditions are given in Table 2 (variants No 1-3).

Table 2. Mechanical properties of different compounding formulas using liquid glass instead of resin in laboratory conditions.

\begin{tabular}{|c|c|c|c|c|c|c|c|c|c|}
\hline \multirow[t]{2}{*}{$\begin{array}{c}\text { Varia } \\
n t\end{array}$} & \multicolumn{3}{|c|}{ Mixture composition } & \multicolumn{6}{|c|}{$\begin{array}{c}\text { Tensile strength, }\left[\mathrm{kg} / \mathrm{cm}^{2}\right] \text { after } \\
\text { interval, }[\mathrm{min}]\end{array}$} \\
\hline & Refractory Filler & Binder & Hardener & 30 & 45 & 60 & 90 & 120 & 180 \\
\hline № 1 & $\begin{array}{l}\text { Molding sand } \\
1 \mathrm{~K}_{2} \mathrm{O}_{3} 03\end{array}$ & Liquid glass & $\mathrm{A} 10+3 \mathrm{CM}$ & 1,3 & 2,0 & 3,6 & 3,9 & 4,6 & 4,9 \\
\hline № 2 & $-/ /-$ & $-/ /-$ & $\mathrm{ACE}$ & 0,6 & 1,4 & 1,8 & 2,2 & 2,7 & 2,9 \\
\hline № 3 & $-/ /-$ & $-/ /-$ & $3 \mathrm{CM}$ & 0,0 & 0,4 & 0,6 & 0,8 & 1,7 & 2,9 \\
\hline № 4 & $-/ /-$ & $-/ /-$ & Katasil & 1,0 & 1,4 & 1,5 & 2,4 & 2,6 & 3,8 \\
\hline
\end{tabular}

Based on the results obtained under the production conditions, that is, on the automatic line, the composition of the mixture, presented in Table 3 (variant № 1), was finally worked out.

At the same time, works to obtain a regenerate from a traditional liquid-glass mixture [20], which could be used as an additive in the manufacturing of a liquid-glass mixture for use in machine molding in the $\mathrm{CO} 2$ process without reducing its properties, were carried out [21]. As a result, it was concluded that the obtained regenerate can be used only as a filling mixture. For this reason, two forms of manufacturing technology were simultaneously used in the workshop, namely:

1-production of safety-free molds on an automatic molding line in accordance with the $\alpha$-set process, using two hardeners of fresh sand and regenerate from the line itself as part of a mixture of liquid glass (Fig. 2) [22]; 
2-mold making on molding machines using a traditional liquid-glass mixture as a facing layer, and as filler, a regenerate obtained from old dumps of a liquid-glass mixture was used.

Table.3. Mechanical properties of various formulations of molding mixtures, using regenerate obtained from the line itself.

\begin{tabular}{|c|c|c|c|c|c|c|c|c|c|c|}
\hline \multirow[t]{2}{*}{$\begin{array}{c}\text { Varia } \\
\text { nt }\end{array}$} & \multicolumn{4}{|c|}{ Mixture composition } & \multicolumn{6}{|c|}{$\begin{array}{c}\text { Tensile strength, }\left[\mathrm{kg} / \mathrm{cm}^{2}\right] \text { after } \\
\text { interval, }[\mathrm{min}]\end{array}$} \\
\hline & $\begin{array}{l}\text { Refractory } \\
\text { Filler }\end{array}$ & Binder & $\begin{array}{l}\text { Hardene } \\
\mathrm{r}\end{array}$ & $\begin{array}{l}\text { Rege } \\
\text { nerat } \\
\text { e, } \\
{[\%]}\end{array}$ & 30 & 45 & 60 & 90 & 120 & 180 \\
\hline № 1 & $\begin{array}{l}\text { Molding } \\
\text { sand } \\
1 \mathrm{~K}_{2} \mathrm{O}_{3} \mathrm{O} 3\end{array}$ & $\begin{array}{l}\text { Liquid } \\
\text { glass }\end{array}$ & $\begin{array}{c}\mathrm{A} 10+3 \mathrm{C} \\
\mathrm{M}\end{array}$ & $70-75$ & $\begin{array}{c}0,8- \\
0,9\end{array}$ & $\begin{array}{l}1,0- \\
1,2\end{array}$ & $\begin{array}{l}1.3 \\
1,4\end{array}$ & $\begin{array}{l}1,6- \\
1,9\end{array}$ & $\begin{array}{l}2,5 \\
2.8\end{array}$ & $\begin{array}{l}3,0- \\
3,6\end{array}$ \\
\hline № 2 & $\begin{array}{l}\text { Regenerate } \\
\text { of a } \\
\text { liquid-glass } \\
\text { mixture }\end{array}$ & $\begin{array}{l}\text { Liquid } \\
\text { glass }\end{array}$ & $\begin{array}{c}\mathrm{A} 10+3 \mathrm{C} \\
\mathrm{M}\end{array}$ & $60-65$ & $\begin{array}{c}0,6- \\
0,8\end{array}$ & $\begin{array}{r}0,8 \\
1,0\end{array}$ & $\begin{array}{r}1,2- \\
1,3\end{array}$ & $\begin{array}{l}1,4- \\
1,6\end{array}$ & $\begin{array}{l}2,0 \\
2,4\end{array}$ & $\begin{array}{r}2,6- \\
3,2\end{array}$ \\
\hline № 3 & $\begin{array}{l}\text { Regenerate } \\
\text { of a } \\
\text { liquid-glass } \\
\text { mixture }\end{array}$ & $\begin{array}{l}\text { Liquid } \\
\text { glass }\end{array}$ & Katasil & $65-72$ & $\begin{array}{c}0,8- \\
0,9\end{array}$ & $\begin{array}{l}1,0- \\
1,2\end{array}$ & $\begin{array}{l}1,1- \\
1,4\end{array}$ & $\begin{array}{l}1,5- \\
1,8\end{array}$ & $\begin{array}{l}2.3 \\
2,6\end{array}$ & $\begin{array}{r}2,8- \\
3,4\end{array}$ \\
\hline
\end{tabular}

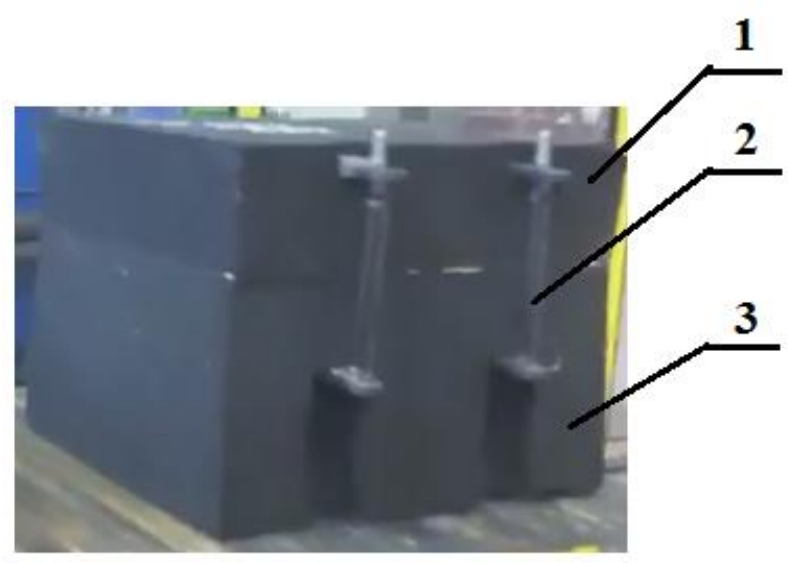

Fig. 2. Complete mold, form made on $\alpha$-set to process: 1 - Top half-mold; 2 - Mechanical fastening of half-molds; 3 - Bottom half-mold

For this reason, it was decided to test the composition of the mixture for the automatic line using as a fresh sand of the regenerate used for the filling mixture in machine molding. A positive result was obtained when using the composition given in table № 3 (variant № 2), which is acceptable for the stable operation of the molding line.

At this time, the Katasil hardener, recommended for a liquid-glass mixture and produced by "Uralchimplast" appeared on the market. The carried-out laboratory research showed that its use, when using fresh molding sand, allows obtaining the following properties, given in Table № 2 (variant № 4). While working on the line itself, a recipe that allows the moulding line to work on a mixture of a liquid-glass mixture consisting of a regenerating mixture (like fresh sand), a liquid glass, the Katasil hardener itself and the regenerate from the line and achieve the necessary mechanical properties of the mixture (Table 3, variant № 3) was chosen.

In addition, the switch to the Katasil hardener simplified the dosage of the hardener in the mixer, because unlike the use of two hardeners, the feeding circuit was much simplified, which meant that its 
stability and reliability increased. In addition, there was only one supplier, which is also important, to ensure the stable operation of the shop. Proceeding from this, the workshop was completely transferred to a single molding and core mix based on the Katasil binder.

Operation of the molding line during the year has shown the stability of the adopted technology, with strict adherence to the requirements for the amount of dust in the regenerate from the line, and has made it possible to master the production of castings from grey and high-strength cast iron of carbon steel, mangalloy and some grades of high-alloy steels [23].

\section{Conclusion}

Based on the above, we can highlight the following conclusions:

1. Applying automatic lines working on the $\alpha$-set process, it is necessary to understand that using Russian molding sands it is impossible to achieve the result promised by the developers of this system (the most unpleasant is the presence of a tangible smell):

2. The use of foreign resins and hardeners does not eliminate the smell problem;

3. The use of resins and hardeners of Russian firms practically does not reduce the properties of the mixture, and allows reducing the cost of their purchase by approximately $20-25 \%$ :

4. The use of automatic moulding lines working in the $\alpha$-set process, in factories, in the foundry production of which the technology of manufacturing liquid-glass mixtures by the $\mathrm{CO} 2$ process was applied, it is really possible to apply the technology of regeneration of old dumps of a liquid-glass mixture and work on an automatic moulding line on a mixture consisting of liquid glass and this regenerate instead of fresh sand.

At the same time, at least two problems are solved:

1. The smell is completely eliminated;

2. The cost of resin and dry fresh sand is reduced.

\section{References}

[1] C. J. Nybergh, AlpHaset process and its use in Russia, The Founder of Russia. 3 (2002) 35-40.

[2] H. Hobelsberger, H. Kroger, D. Nisi, Initial experience with an advanced environmentally friendly cold box system at Daimler-Benz, Giesserei. 84 (1997) 48-49.

[3] J. W. Sutherland, K. L. Gunter, Enviromental Attributes of Manufacturing Processes, Graduate Research Fellow Department of Mechanical Engineering, 13 (2001) 293-316.

[4] J.R. Brown, Foseco Ferrous Foundryman's Handbook, Butterworth Heinemann, Oxford, 2000.

[5] A. Dioszegi, J. Svidro, T. Ferenczi, The effect of different binder levels on the heat absorption capacity of moulding mixtures made by the phenolic urethane cold-box process, Journal of Thermal Analysis and Calorimetry December. 130 (2017) 1769-1777.

[6] S. S. Jukovskii, Technological indexes synthetic binding made by the Uralkhimplast-Kavenagi enterprise, The Founder of Russia. 4 (2007) 29-32.

[7] I. Vaskova, M. Smolkovab, J. Malika, Experience in forming and core mixtures by Alphaset technology archives of foundry engineering, S. Eperjesic a Department of Ferrous Metallurgy and Foundra, 8 (2008) 141-144.

[8] J.T. Svidro, The effect of different binder levels on the heat absorption capacity of moulding mixtures made by the phenolic urethane cold-box process, Journal of Thermal Analysis and Calorimetry. 130 (2017) 1769-1777.

[9] V.A. Kukartsev, Alphaset- process and forming sands of Russia, Procuring production. 3 (2014) 45-47.

[10] P.A. Borsuk, A.S. Kaftannikov, Use of cold hardeners mixes at the enterprises of Russia, The Founder of Russia. 10 (2004) 30-33.

[11] T. Penko, Resin/ $/ \mathrm{CO}_{2}$ Core and Moldmaking Process: Emission Characterization, American Foundry society. 10 (2005) 1029-1037.

[12] Information on http://www.metallicecheckij-portal.ru 
[13] V.A. Kukartsev, Liquid glass mixes and the modern hardeners, Founder of Russia. 10 (2013) 46-48.

[14] M.V. Ramana, Optimization of process parameters of $\mathrm{CO}_{2}$ moulding process for better knockout property, International Journal of Advanced Technology in Engineering and Science. 12 (2014) 2348-7550.

[15] J. Orkas, Technical and environmental requirements for surplus foundry sand utilization, Helsinki University of Technology, Espoo, Finland, 2001.

[16] P.S. Zinchenko, M.P. Aksenenko, A.V. Yovbak, U.V. Orendarchuk, Use of liquid glass mixes with the under content of liquid glass as factor of upgrading of mold pieces of machine-building appointment, Science Rise, 2 (2016) 6-9.

[17] S.S. Tkachenko, V.S. Krivitckii, U.N. Muravyev, G.A. Kolodii, Revival in machine-tool construction of technology of shaping on the basis of inorganic components, Foundry production. 5 (2017) 5-10.

[18]. I. Gross, F. Voldert, The modern revitalization system of forming mix on the basis of furan resins, the Founder of Russia. 3 (2013) 19-20.

[19] E.A. Chernyshev, A.A. Evlampiyev, A.V. Korolev, S.A. Kuznetcev, L.A. Ivanova, About modernization of steel departments with use of the modern technologies of shaping, Foundry production, 3 (2015) 36-38.

[20] V.A. Kukartsev. T.N. Drozdova, V.V. Kukartcev, A.V. Atroshenko, Use of dumps of waste liquid glass mix at manufacture of forms in foundry production, Foundry production. 5 (2015) 6-8.

[21] M. VenkataRamana Principal, Modelling of $\mathrm{CO}_{2}$ moulding process, Global Journal of Advanced Engineering Technologies. Special Issue (2014) 2277-6370.

[22] S.S. Gukovskii, Cold harden binding and mixes for wafer cores and forms, Mechanical engineering. 2010.

[23] E.A. Chernyshev, A.A. Evlampiyev, A.V. Korolev, S.A. Kuznetcev, L.A. Ivanova, About modernization of steel departments with use of the modern technologies of shaping, Foundry production, 3 (2015) 36-38. 